\title{
Manuscrito aceito
}

\section{Criação e desenvolvimento do Laboratório de Genética no Instituto Butantan}

I. A participação de Gerta von Ubisch

Mario Gustavo Mayer ${ }^{1}$, Eny Stanger Ferreira², Nelson Ibañez ${ }^{3}$

${ }^{1}$ Centro de Memória, Instituto Butantan, pesquisador científico, biólogo, mestre. mario.mayer@butantan.gov.br, Avenida Vital Brasil, 1500 - Butantan - SP CEP 05503-900

${ }^{2}$ Centro de Memória, Instituto Butantan, Arquivista, bacharel em Biblioteconomia.

3 Professor Adjunto da FCM da Santa Casa de São Paulo, médico sanitarista, livre docente pela FSP USP SP.

Este artigo foi avaliado, revisado por pares e aceito para publicação. Ele está em processo final de publicação e pode sofrer alterações.

O artigo é considerado publicado na edição 14(1) dos Cadernos de História da Ciência e está registrado com o DOI:

https://doi.org/10.47692/cadhistcienc.2020.v14.34751

\section{Resumo}

O presente artigo apresenta a primeira inserção formal da disciplina de Genética no Instituto Butantan evidenciada pela criação do Laboratório de Citologia, Embriologia \& Genética Experimental, em 1935, durante a primeira gestão de Afrânio do Amaral (1928-38) como diretor do instituto. Mais especificamente, analisa-se a montagem desse laboratório e os frutos da pesquisa realizada pela geneticista alemã de origem judaica Gerta (também Gertrud) von Ubisch, a primeira mulher a ter a licença para lecionar na Universidade de Heidelberg e, ex-assistente de Carl Correns, um dos responsáveis pela redescoberta das Leis de Mendel. Além dos motivos de sua emigração e breve história na Alemanha, este artigo relata as propostas iniciais de pesquisa feitas por Afrânio e como a cientista se ajustou para o 


\title{
Manuscrito aceito
}

cumprimento destas tarefas. O artigo ainda contextualiza sua produção através de relatos das condições de trabalho, associação com outros pesquisadores alemães e brasileiros, além do cenário político brasileiro, estadual e institucional, nesse período. Nosso objetivo maior é o resgate da memória do Instituto Butantan. Uma abordagem para esse resgate é através da história de seus laboratórios. Aqui, utilizamos o Laboratório de Genética como um plano piloto com esse objetivo. O trabalho de Gerta von Ubisch é a primeira página da história do Laboratório de Genética do Instituto Butantan, ainda ativo nos dias de hoje.

Palavras-chave: Gerta von Ubisch. História da ciência. Laboratório de Genética. Instituto Butantan

\begin{abstract}
The present article introduces the first formal basis of the Genetics discipline at the Butantan Institute evidenced by the creation of the Laboratory of Cytology, Embryology \& Experimental Genetics in 1935, during the first period of the director Afrânio do Amaral (1928-38). Actually, the article reports the setting up of this laboratory and the fruits of the research carried out by the German geneticist of Jewish origin Gerta (also Gertrud) von Ubisch, the first woman to have a license to teach at the University of Heidelberg and, former assistant to Carl Correns, one of the responsibles for the rediscovery of Mendel's Laws. In addition to the causes for her emigration and a brief history in Germany, the article reports the initial research proposals made by Afrânio and how the scientist adjusted herself to fulfill these tasks. Still, this article presents her production through reports of working conditions, association with other German and Brazilian researchers in addition to the Brazilian, São Paulo (state, province) and institutional political scenario at that time. Our main objective is to rescue the memory of the Butantan Institute. One way to get this objective is through the history of their laboratories. We used the Genetics Laboratory as a pilot plan for this purpose. Gerta von Ubisch's research is the first page of the history of the Genetics Laboratory of the Butantan Institute, still active today.
\end{abstract}




\section{Manuscrito aceito}

Keywords: Gerta von Ubisch. History of Science. Genetics Laboratory. Instituto Butantan.

\section{Introdução}

Esse artigo visa contribuir para a construção da memória institucional do Instituto Butantan (IBU) a partir do regaste histórico da gênese de seus laboratórios, respectivas áreas de pesquisa e os pesquisadores e atores responsáveis. No caso específico deste artigo, buscam-se as raízes do atual Laboratório de Genética do Instituto Butantan, assim como a primeira inserção dessa disciplina na instituição. Um exame dos Relatórios de Gestão aponta para a criação da Secção de Citologia, Embriologia \& Genética Experimental no Instituto Butantan na década de $1930^{1}$, na primeira gestão de Afrânio do Amaral (1928-38), e o papel que tinha como liderança científica a pesquisadora alemã Gerta von Ubisch (também Gertrud von Ubisch, Figura 1) nesse processo.

O projeto de reestruturação do Instituto em 1931 liderado por Afrânio do Amaral com a criação do "Centro de Medicina Experimental" apontava para os seguintes pontos que deveriam ser implementados nos anos seguintes: aumento do aporte financeiro; implantação das seções de Botânica Médica, Fisiopatologia Experimental, Química, Farmacologia e Citologia, Embriologia \& Genética; estabelecimento outras fontes de recursos para a manutenção do Instituto, tais como a venda de plantas medicinais e outros produtos. Para tanto, foi efetuada a contratação de cientistas estrangeiros pelo Instituto Butantan. Essas contratações acompanham a criação da Universidade de São Paulo em 1934 dentro do espírito da reforma Francisco Campos de 1931, da qual fez parte a Faculdade de Filosofia, Ciências e Letras, voltada para formação de professores, mas também para a realização de pesquisas em áreas desagregadas das faculdades tradicionais de Direito, Medicina e Engenharia. Nesse sentido, chegaram ao Instituto as lideranças na área de

\footnotetext{
${ }^{1}$ Decreto N4.998 de 27 de abril de 1931. Artigo 40ㅇ - A secção de Cytologia, Embrylogia e Genética Experimental.
} 


\section{Manuscrito aceito}

Química e Farmacologia Experimentais ${ }^{2}$, Botânica Médica ${ }^{3}$ e para a Seção de Genética, a pesquisadora alemã Gerta von Ubisch.

A criação dessas novas áreas, especificamente a de genética no Instituto, sob lideranças estrangeiras, e contextualizadas pelas condições objetivas de desenvolvimento de pesquisas básicas e de sua trajetória institucional, faz com que contemos com alguns referenciais teóricos como o conceito de "ciência em construção" utilizado por Bruno Latour (2000), o qual contempla uma rede de agentes para construção da ciência. Outro autor que corrobora com a ideia de uma rede de agentes para a construção da ciência é Thomas Kuhn, principalmente ao defender a ideia de a ciência ser construída por paradigmas desenvolvidos dentro de uma comunidade científica, ou seja, a comunidade científica é produtora e legitimadora do conhecimento científico. Kuhn ainda defende que o método científico não é isento das relações em que o cientista está inserido (KUHN, 2006).

A proposta de análise objetiva investigar como se deu, na prática, o processo de construção da área de genética e dos fatos científicos em cada gesto dos cientistas dentro e fora de seus laboratórios. O artigo ainda se interessa pelas controvérsias e disputas que ocorreram, permitindo a identificação de problemas e soluções que fogem da linearidade $e$ reducionismo e centram-se na ação dos indivíduos envolvidos e os resultados produzidos empiricamente. Do ponto de vista metodológico, segundo Latour, esta seria a única maneira de compreender a realidade dos estudos científicos, já que a ciência é fundada sobre uma prática e não somente sobre ideias (LATOUR, 2000).

Dois contextos históricos são importantes para registro de sua passagem no Instituto Butantan. Um é o europeu, com o crescimento de regimes totalitários, em especial na Alemanha com a ascensão de forças

\footnotetext{
${ }^{2}$ Karl Heinrich Slotta (1935-38), vindo da Universidade de Bresslau, na Alemanha, descobridor do hormônio feminino, progesterona, tendo como seus assistentes Klaus Neisser (1937-38) e Gherard Szyszka (1935- 38), os quais conseguiram isolar a crotoxina, proteína tóxica do veneno da cascavel, com a colaboração do pesquisador húngaro Dioniso von Klobusitsky (1931-38), Sara Kaufmann (1931-35), Paulo Köenig (1935 -38) e Heinz Fraenkel-Conrat (1937-39). (Ibañez et. al., 2006; Hawgood, 2001).

${ }^{3}$ Waldemar Peckolt (1934-36), médico dedicado ao estudo de plantas medicinais brasileiras, assim como seu pai, o farmacêutico Gustavo Peckolt, e seu avô, o renomado Theodoro Peckolt, que era farmacêutico e botânico alemão, colaborador de Carl Friedrich Philipp von Martius.
} 


\section{Manuscrito aceito}

nazistas e perseguição aos descendentes judeus. $O$ outro é brasileiro que, no período de sua permanência na Instituição (25/03/1935 a 23/06/1938), ocorre 0 processo conhecido como o "Caso Butantan", envolvendo questionamentos de natureza político institucional sobre a atuação do então Diretor, Afrânio do Amaral. No Brasil, ainda vigorava o "Estado Novo", período de exceção decretado por Vargas.

Este artigo foi composto a partir de pesquisa de material documental do Instituto, relatórios de gestão do período, documentos da seção de pessoal, acervo iconográfico, trabalhos publicados no período, bem como a pesquisa bibliográfica de publicações nacionais e estrangeiras referentes à cientista, além de seus relatos pessoais e impressões sobre a constituição da área. $\mathrm{A}$ ênfase centrada na cientista também tem como objetivo de ressaltar uma das poucas lideranças femininas do período e sua importância para a área de genética.

\section{Breve biografia e contexto para a vinda de Gerta ao Brasil}

Gerta chega ao Brasil no início de 1935 com 52 anos de idade, trazendo em seu currículo experiências científicos em diferentes instituições e, em específico na área de genética, ainda em construção nesse período.

Gerta von Ubisch nasceu em 03/10/1882 em Metz, na Alemanha. Pertencente a uma família protestante, tinha ascendência judaica pelos avós maternos (DEICHMANN, 1996). Iniciou seus estudos em Física, graduando-se com um Ph.D em 1911. Decepcionada com seus estudos, que em sua própria opinião não a habilitariam a ter uma carreira sólida em Física, optou por mudar para a área de Botânica. A partir de 1912, Gerta teve passagens pelo Colégio Agrícola de Berlim, trabalhando com Erwin Baur ${ }^{5}$ e sendo a primeira colaboradora mulher a ser aceita pelo mesmo (DEICHMANN, 2014). Baur se

\footnotetext{
${ }^{4}$ Ver Ibañez, Nelson; Fernandes, Suzana Cesar Gouveia; Faria, Marcella; Wen, Fan Hui e Sant'Anna, Osvaldo Augusto (2006). De Instituto Soroterápico a Centro de Medicina Experimental: institucionalização do Butantan no período de 1920 a 1940. Cad. Hist. Ciênc. vol.2 no.1 São Paulo.

${ }^{5}$ Erwin Baur, é considerado o pai da genética de plastídios, que fogem às proporções mendelianas. Ele obteve a cadeira de professor titular de genética em 1911 no Colégio Agrícola de Berlim, tornando-se posteriormente diretor do primeiro Instituto de Pesquisa em Hereditariedade, fundado como parte do Colégio Agrícola.
} 


\section{Manuscrito aceito}

notabilizaria posteriormente por ter a maioria do seu grupo de colaboradores do género feminino, contando com, além de Ubisch, Elisabeth Schiemann, Louise von Graevenitz, Emy Stein e Paula Hertwig (STAMHUIS; VOGT, 2017). Até a metade do século passado nos países ocidentais, geralmente as mulheres cientistas eram mais numerosas em áreas descritivas, tais como Antropologia, Astronomia e Botânica, apesar de algumas se destacarem notavelmente em ciências experimentais tais como Marie Curie (1867-1934), Joliot Curie (18971956), Lise Meitner (1878-1968) e Dorothy Crowfoot Hodgkin (1910-1994), todas no campo da Física. Discute-se se a genética seria um novo nicho para cientistas experimentais do gênero feminino (DEICHMANN, 2014) pelo fato de ser ainda uma ciência muito jovem e em desenvolvimento inicial. Diante das poucas possibilidades de ascensão na carreira e pelo fato de a posição de assistente ser exclusivamente reservada a agrônomos no Colégio de Agricultura, ela se transferiu em 1914 para o recém-fundado Instituto Kaiser Wilhelm de Biologia como assistente de Carl Correns, um dos responsáveis pela redescoberta das Leis de Mendel. Após o início da Primeira Guerra Mundial, ela deixou o Instituto Kaiser Wilhelm e passou a trabalhar em várias companhias de melhoramento de plantas (1915) até obter, em 01/05/1921, a posição de assistente no Instituto de Botânica de Heidelberg sob supervisão de Ludwig Jost ${ }^{6}$. Jost foi responsável por sua habilitação ("Habilitationen", direito de candidatar-se a professor) no campo da botânica em 1923. Em 1929 ela recebeu o título de professora associada extraordinária sem ser titular da cátedra ("non-tenured"). Jost se referiu à sua habilitação como "superb" e não teve dúvidas em recomendá-la como professora associada ("tenured"). No entanto, ele mesmo não acreditava que ela pudesse se tornar uma professora titular, assim como nenhuma mulher tinha a possibilidade de se tornar uma diretora em um Instituto de Botânica. De fato, durante os anos em que trabalhou como professora assistente, Ubisch não recebeu qualquer indicação para alguma cadeira de alguma das grandes universidades. Ela declarou que isso pode ter se dado por dois motivos: 1) seria praticamente impossível alguma mulher obter a maioria dos votos numa faculdade, e 2) poucas vagas

\footnotetext{
${ }^{6}$ Ludwig Jost foi estudante de Ciências Naturais em Heidelberg. Entre 1919 e 1934 foi professor titular da cadeira de Botânica em Heidelberg. Era especializado em Morfologia, Histologia e Fisiologia de Plantas.
} 


\title{
Manuscrito aceito
}

no campo da genética eram disponíveis em orçamentos dessas universidades, sendo essa área preenchida por professores de Botânica e Zoologia (DEICHMANN, 1996). Até 1945, nenhuma bióloga receberia o título de professora titular em 22 universidades alemãs (DEICHMANN, 2014). Um trecho da opinião de Jost é representativo da desproporcionalidade no julgamento da produção do gênero feminino nas ciências à época. Na avaliação da habilitação de Gerta, ele escreve:

\begin{abstract}
"It's clear that one must be particularly critical in approaching the application for "Habilitation "of a woman. The decision is made easier in this case since there are so many accomplishments. It's therefore not necessary to build on hopes as usually is the case with "Habilitations, rather one can say that the scientific development has reached a high point "(JOST, 1922 apud DEICHMANN, 1996).
\end{abstract}

Ubisch trabalhou durante 12 anos na Universidade de Heidelberg, sendo a primeira mulher nesta universidade e em todo estado de Baden-Wüttemberg a receber uma permissão para lecionar (DEICHMANN, 1996; REMY, 2002). No que se diz respeito ao seu objeto de trabalho específico, Ubisch se dedicou a estudos de fatores genéticos de cevada, descrevendo um fenômeno que desviava significativamente das proporções mendelianas. ${ }^{7}$

Após a "Lei do Serviço Público" alemã, a qual também se aplicou a empregados de universidades como assistentes e professores, Ubisch teve seu contrato rescindido em 20/04/1933 baseando-se no fato de ser descendente "não-ariana". Vários professores pleitearam sua permanência na universidade. $\mathrm{Na}$ visão de Ubisch, apesar dos esforços realizados por Jost junto ao reitor para a sua permanência, movimentos contrários, inclusive da Organização Estudantil Nacional Socialista, provocaram um boicote a suas aulas e determinaram que elas fossem encerradas por um semestre

\footnotetext{
${ }^{7}$ Ubisch, Gerta von. 1919. “II. Beitrag zu einer Faktorenanalyse von Gerste. Zeitschrift fürinduktive Abstammungs- und Verelehrerbungslehre 20: 65-117. Neste trabalho, ela estudou ligação de fatores genéticos em cevada. Ubisch, Gerta von. 1934. "Das fertilitätsproblem im pflanzenreich" . Zeitschrift fürinduktive Abstammungs- und Verelehrerbungslehre 67: 225-241. "O problema da fertilidade no reino vegetal”. Heterostilia e distribuição sexual irregular em Antennaria (1934). Heterostilia refere-se a diferenças no comprimento de estames e estilete em certas flores.
} 


\section{Manuscrito aceito}

(DEICHMANN, 1996). Em 1935, de acordo com a Lei do Cidadão do Reich, a universidade obrigatoriamente a teria privado do direito de ensinar.

Consciente da nazificação das instituições de ensino e pesquisa, no verão de 1933 Ubisch parte em busca de algum cargo fora da Alemanha após deixar Heidelberg. Ela aceitou um convite da Associação Holandesa de Mulheres Acadêmicas para passar um semestre em Utrecht e recebeu uma bolsa na Suíça para o semestre de verão de 1934. Gerta teve grande dificuldade em conseguir uma posição permanente fora da Alemanha e não foi escolhida para uma cadeira em Fisiologia de Plantas na África do Sul apesar das recomendações de Jost (DEICHMANN, 1996; REMY, 2002).

Com a mediação de Ernest Bresslau, um zoólogo amigo da família von Ubisch que fora demitido de Colônia por ser descendente de judeus e já havia emigrado para o Brasil, foi oferecido a Gerta, em dezembro de 1934, um cargo de chefe da Seção de Genética no Instituto Butantan em São Paulo (RICHTER; SCHLECHTER, 2011). Ainda que alertada por holandeses sobre a pouca confiabilidade das autoridades brasileiras, por se tratar de uma terra de tradição latina onde não era comum se ver uma mulher bem qualificada trabalhando em atividades de maior exposição, Gerta decidiu vir para o Brasil. O desejo de voltar a ser independente aliado à perspectiva de estudo da grande diversidade da vegetação local, uma vez que Gerta tinha formação em Botânica, foram importantes em sua decisão (RICHTER; SCHLECHTER, 2011).

\section{A chegada de Gerta ao Butantan}

Seu padrinho Ernest Bresslau já havia visitado o Brasil e contou com o apoio de Teodoro Ramos, um matemático e amigo que havia sido incumbido de contratar um zoólogo, um botânico e um químico na Europa para a formação do embrião da Universidade de São Paulo (USP). Uma boa oportunidade se apresentou para o Brasil com o êxodo de cientistas alemães após a ascensão de Hitler, da mesma forma que também era conveniente aos próprios cientistas. Foram contratados para a USP Bresslau como zoólogo, Rawitscher, de Friburgo, como botânico e Reinhold, de Bonn, como químico. Esses três acadêmicos chegaram ao Brasil em junho de 1934, sendo que os 


\section{Manuscrito aceito}

dois últimos foram contratados como professores associados. Além de suas nomeações como catedráticos, pouco apoio Ihes foi dado após a morte repentina de Ramos depois de sua chegada. Em dezembro de 1934, Bresslau enviou uma carta a Gerta quando a mesma estava em Utrecht confirmando uma vaga destinada a ela no Instituto Butantan.

Era do conhecimento de Gerta que o Instituto Butantan, famoso pela produção de soro antiofídico, também se destinava à produção de soros e vacinas para várias doenças humanas, além de realizar experimentos relacionados à essas doenças (RICHTER; SCHLECHTER, 2011). Havia também um departamento de pesquisa sobre plantas medicinais ainda muito baseada na cultura popular indígena, sendo desejável uma botânica como Gerta para submeter esses conhecimentos a uma investigação estritamente científica (RICHTER; SCHLECHTER, 2011).

Bresslau aconselhou a Gerta que ocupasse a vaga e partir para o Brasil o mais rápido possível, devido a uma certa fama de volubilidade no trato dessas coisas por parte dos brasileiros à época. Mais tarde, Gerta testemunhou muitos amigos serem chamados a São Paulo e, depois de confirmarem o convite, nunca mais ouvirem falar a respeito do assunto. Visto que a situação não se mostrava favorável à Gerta na Europa, ela partiu de Utrecht, na Holanda, em uma viagem um tanto turbulenta num pequeno cargueiro. Após escala em Montevidéu chegou ao porto de Santos, no Brasil (RICHTER; SCHLECHTER, 2011).

Em Santos, Bresslau e Dr. Afrânio do Amaral, Diretor do Instituto Butantan, a esperavam. Durante o primeiro almoço no Brasil, Dr. Afrânio definiu qual seria sua função no Instituto Butantan: criar cavalos que fossem melhores produtores do melhor soro e produção de aveia para alimentá-los. Gerta ficou extremamente surpreendida, devido ao fato de ter formação muito sólida em genética de plantas, mas Bresslau sussurrou a ela: "Em terra de cego, quem tem um olho é rei". E ela pensou consigo mesma: "No fim, só existe uma Genética para o ser humano, os animais e as plantas" (RICHTER; SCHLECHTER, 2011), raciocínio este que viria a ser repetido posteriormente por Afrânio do Amaral em sua defesa no "Caso Butantan", mais 


\section{Manuscrito aceito}

especificamente em sua publicação "Serpentes em Crise" (AMARAL, 1941), como discutiremos adiante.

\section{O trabalho de Gerta no Butantan}

Gertrud von Ubisch foi contratada aos 52 anos, em 25/03/1935, pelo Governo do Estado de São Paulo para exercer o cargo de assistente por tempo indeterminado. Formalmente, o início do seu exercício se deu em 01/03/1935 na Seção de Citologia, Embriologia e Genética Experimental do Instituto Butantan. O contrato foi lavrado na Secretaria de Estado da Educação e da Saúde Pública, quando o secretário era Marcio Munhoz e o governador era Armando de Sales Oliveira (INSTITUTO BUTANTAN, 1935b). No entanto,

Gertrud von Ubisch iniciou seus trabalhos apenas em outubro deste ano, quando são disponibilizadas as dependências laboratoriais definitivas. Ela já não contava mais com o apoio de Bresslau, falecido em 09/05/1935. Infelizmente, a seção que ela recebeu ficava numa pequena casa afastada, o que dificultou a sociabilização com seus colegas. Além da sua seção, havia apenas o Departamento de Botânica Medicinal separado do resto. A estrutura laboratorial consistia apenas de duas salas vazias: na menor, uma escrivaninha; na maior, uma prateleira para os seus próprios livros, um armário vazio e uma mesa. Na verdade, não havia verba para essa nova Seção, que deveria ter sido solicitada ao ministério durante ano anterior. Isso não aconteceu, pois somente em dezembro, quando o Diretor Afrânio do Amaral teve conhecimento de Gerta através de Bresslau, é que começou a arranjar a liberação do local para realizar seu tão esperado sonho de uma Seção de Genética no Instituto, assim como verba para seu salário (INSTITUTO BUTANTAN, 1935; RICHTER;SCHLECHTER, 2011).

A avaliação do Instituto Butantan por Gerta era a de que, para os padrões brasileiros, o nível científico do Butantã era muito alto. Ficava próximo ao nível do famoso Instituto Manguinhos, fundado por Oswaldo Cruz no Rio de Janeiro, cujas pesquisas, ela sabia, levaram a cidade contaminada pela peste à completa recuperação. Segundo ela mesma, os melhores profissionais do Instituto Butantan também estudaram no Instituto Manguinhos: o entomologista 


\section{Manuscrito aceito}

Flávio de Fonseca ${ }^{8}$, o endocrinologista Thales Martins ${ }^{9}$ e o imunologista Travassos da Rosa ${ }^{10}$. Esses três nomes a ajudaram muito em seu trabalho: "sem eles, teria sido impossível conseguir os animais e viveiros necessários" (RICHTER; SCHLECHTER, 2011).

Fica claro que, apesar de se tratar de uma Seção de Citologia, Embriologia e Genética Experimental, faltavam equipamentos e insumos para o estudo de Citologia e Embriologia. Assim, iniciou trabalhos práticos na área de genética basicamente em duas frentes: seleção de forrageiras fundamentais para alimentação de cavalos e seleção de cavalos bons produtores de soro (INSTITUTO BUTANTAN, 1935). É curioso notar que, em todos os relatórios enviados ao Diretor de 1935 a 1937 e assinados por Gertrud von Ubisch, a Seção em questão não é grafada como Seção de Citologia, Embriologia e Genética, mas sim como Seção de Genética Experimental (1935 e 1937) ou simplesmente Seção de Genética (1936), sugerindo que a expressão no nome da seção nesses relatórios não fosse nada além da soma da expertise da sua atual chefe e da necessidade dos estudos que viriam a ser realizados para 0 Instituto (INSTITUTO BUTANTAN, 1935;1937).

No que diz respeito à seleção de forrageiras, a aveia e o milho foram os escolhidos. A intenção mais específica era a de iniciar seleção, cruzamento e cultivo de espécies propícias à terra e ao clima local. No caso da aveia, Gertrud fez vir da América do Norte, da Itália e da Alemanha qualidades diferentes e linhagens puras em grande quantidade. No entanto, como a casa de isolamento para as plantas amadurecidas não ficou pronta a tempo, os pássaros locais consumiram quase todas as sementes dessas plantas. $\mathrm{Ou}$ seja, como se não bastasse a ausência de materiais importantes para os estudos de Citologia e Embriologia, praticamente obrigando-a a refugiar-se na área de Genética - ainda que essa fosse sua especialidade -, questões

\footnotetext{
${ }^{8}$ Flávio Oliveira Ribeiro da Fonseca (1900-1963) foi médico, parasitologista e microbiologista. Dirigiu o Instituto Butantan pela primeira vez de 1941 a 1944 e, pela segunda vez, de 1956 a 1963. Foi um dos fundadores da Escola Paulista de Medicina e fazia parte do corpo docente da Faculdade de Medicina Veterinária da USP. Produziu estudos importantes associados à acarologia e malária.

9 Thales César de Pádua Martins (1896-1979), renomado fisiologista de Manguinhos, veio para São Paulo assumir como AssistenteChefe a Seção de Fisiopatologia do Instituto Butantan (1935-1937), coordenando estudos na área de endocrinologia e, posteriormente, assumindo a Cátedra de Fisiologia da recém fundada Escola Paulista de Medicina.

${ }^{10}$ Joaquim Travassos da Rosa (1898-1967) foi contratado para Assistente do Instituto Butantan em São Paulo no dia 24 de junho de 1929 e, após concurso para a Secção de Vírus e Rickéttsias, foi nomeado Assistente-Chefe em 17 de janeiro de 1936. Em outubro de 1948, foi comissionado pelo Ministério da Educação e Saúde para instalar e organizar a Secção da Rickéttsias do Instituto Oswaldo Cruz. Em 1952, ocupou a chefia da Divisão de Vírus do Instituto de Microbiologia da Universidade do Brasil.
} 


\section{Manuscrito aceito}

relacionadas à infraestrutura do Instituto para adotar a vertente de estudos genéticos em forrageiras teriam que ser solucionadas, tais como a adoção de uma simples gaiola de isolamento. Procedimento semelhante à aveia foi adotado com o milho, quando foram utilizadas variedades brasileiras e norteamericanas (INSTITUTO BUTANTAN, 1935).

\section{Modelos animais experimentais: cavalos ou preás?}

Com relação à seleção de mamíferos, Gerta teve que adequar experimentos que prospectariam bons produtores de soro a um sistema que não fosse de cavalos, uma vez que cavalos possuem uma reprodução muito lenta e um período de desenvolvimento longo. Uma égua pode ter, na melhor das hipóteses, um potro por ano. Como os pais não eram de nenhuma linhagem pura, cada potro teria suas individualidades e, por isso, não seriam apropriados para experimentos genéticos. Como veio a saber posteriormente, não seria possível fazer soros em cavalos com menos de 10 anos, uma vez que morreriam com o veneno injetado, sem exceções. Dessa forma, seria impossível conseguir um resultado utilizável através de cruzamentos dentro do período de vida de um pesquisador. Por isso, ela teria que trabalhar com mamíferos de reprodução mais rápida e prole mais numerosa.

Em uma caminhada junto com Thales Martins assim que chegou ao Instituto, Gerta observou pequenos mamíferos selvagens, que veio a saber eram denominados preás. Em sua biografia, Gerta relata que, após Thales Martins informá-la de que esses pequenos animais estavam por todo território do Instituto, ela se deu conta do que seria mais adequado a se fazer. Em preás (Cavia aperea), o período gestacional é de aproximadamente dois meses, podendo-se obter até meia dúzia desses por geração. Se fatores genéticos tivessem influência na maior produção, e produção de soros com maior poder de neutralização, seria de se esperar uma correspondência entre esses fatores de preás e os de cavalos. Utilizavam-se cavalos para produção de soro porque obtinha-se 1,5L de sangue, o que é bastante comparando-se aos poucos centímetros cúbicos obtidos em preás; e não porque preás não eram adequados para a produção experimental de soros. 


\section{Manuscrito aceito}

O estudo teve início em 1935 com a detecção das propriedades sorológicas dos preás selvagens, vislumbrando o cruzamento posterior destes com linhagens de cobaios domesticados (porquinhos-da-Índia) e a observação de variantes na quantidade e qualidade de soros obtidos. No entanto, dificuldades se apresentaram desde o início, como relatado pela própria cientista. A obtenção de preás, assim como sua manutenção, deveria ser feita por alguém que soubesse como fazê-las, o que significava a necessidade de um ajudante dedicado a isso. Ademais, após a ideia ser divulgada internamente, outros pesquisadores se interessaram pelo mesmo animal e, tendo maior prestígio entre trabalhadores subalternos, tinham a preferência destes. No entanto, uma circunstância a auxiliou. Ao contrário dos domesticados muito mansos, os preás selvagens tentavam escapar de qualquer forma e deveriam ser alimentados de variadas maneiras. Por esse motivo, Travassos, que trabalhou com o perigoso tifo exantemático de São Paulo, não podia mantê-los em seus viveiros externos, pois um animal que fugisse colocaria todos em risco de vida. No entanto, Gerta poderia mantê-los em gaiolas de zinco dentro do laboratório sem risco, uma vez que seu material experimental não oferecia os mesmos riscos que o material de Travassos. Assim, Travassos cedeu a Gerta todos os 50 preás que acabaram em suas mãos, originalmente capturados para ela, além dos viveiros externos, os quais também não poderiam ser utilizados por ele (RICHTER; SCHLECHTER, 2011).

Deve-se ainda ressaltar que, além do objetivo prático na elucidação de fatores genéticos importantes na produção de soros, a utilização de cobaios guardava uma questão de pesquisa básica importante. Deve-se considerar que, naquele momento da genética básica, muitos conhecimentos eram adquiridos através de cruzamentos entre espécies diferentes de plantas ou animais do mesmo gênero com o objetivo de estabelecer quais seriam da mesma espécie. Nesse contexto, o cruzamento de cobaios domesticados Cavia porcellus (Linné) - e seus prováveis antecessores preás selvagens Cavia rufescens (Lund) - poderiam oferecer contribuição à genética clássica do gênero em questão (UBISCH; AMARAL, 1935-1936). 


\section{Manuscrito aceito}

\section{Estudos a terminar e outros trabalhos}

Era esperado que Gerta ainda tivesse estudos a terminar que a acompanharam da Alemanha para o Brasil. De fato, após receber plantas de suas experiências da Alemanha, Gerta terminou no ano de 1935 seus estudos sobre a genética de Antennaria dioica, denominada popularmente no Brasil como "Pé de Gato" devido à aparência de seus pequenos capítulos florais. Anteriormente, entre 1930 e 1934, von Ubisch havia publicado três artigos cujos temas eram a relação entre cor e sexo, a proporção dos sexos, e a hereditariedade desses caracteres em Antennaria dioica ${ }^{11}$.

No Brasil, ela finalizou esses estudos descrevendo formas hermafroditas dessas plantas, assim como sugerindo uma base genética para essas formas através de estudos genéticos baseados em vários cruzamentos. Esses resultados foram publicados nas revistas Genetics e Memórias do Instituto Butantan (UBISCH, 1935; UBISCH, 1935-1936).

Apesar de a genética de sorologia de mamíferos e a genética de forrageiras com finalidades de produção terem objetivos específicos, Gerta se entusiasmava com a diversidade de plantas e possíveis estudos genéticos relacionados às mesmas, como ela mesma havia vislumbrado antes de viajar para o Brasil. Assim, ela iniciou o cultivo de mamão para elucidar as relações sexuais da espécie, iniciando também uma pesquisa citológica desse gênero de planta (INSTITUTO BUTANTAN, 1935).

Da mesma forma, interessava-se por fatores que podem reduzir a produção de forrageiras. No Brasil, iniciou estudos com uma praga vegetal importante, os fungos Ustilaginales, que atacam praticamente todas as plantas cultivadas tais como aveia, trigo, centeio, cevada, milho, arroz, cana-de-açúcar e capim, podendo prejudicar consideravelmente a produção. Gerta já havia tido

\footnotetext{
${ }^{11}$ Von Ubisch, 1930. Geschlechtsverteilung und secundare Geschlechtsmerkmale bei Antennaria dioua. Biol. Zbl. 50: 532-540.

Von Ubich, 1932. Selbstfertilitat und Geschlechtsverhaltnis bei Antennaria dioica. Biol. Zbl. 52: 307 312.

Von Ubisch, 1934. Das FertiliEtsproblem im Pflanzenreiche. Z. i. A. V. 67: 225-241.
} 


\section{Manuscrito aceito}

contato com esses fungos em Zurich no ano de 1934. No Canadá, de 1910 a 1911, o prejuízo atribuído à essa praga foi de 33 milhões de dólares. Gerta utilizou oxalidáceas brasileiras, tais como trevos e azedinhas presentes no campus do Instituto, como modelo para verificar a influência da infecção de Ustilago na reprodução dessas plantas, mais especificamente no padrão de heterostilia (Instituto Butantan, 1935). Esses resultados foram apresentados presencialmente pela pesquisadora e constam nos anais da primeira reunião de fitopatologistas do Brasil (Figura 2) em 22/01/1936, promovida pelo Instituto de Biologia Vegetal do Ministério da Agricultura no Rio de Janeiro, quando, durante a Era Vargas, o Ministro da Agricultura era o Dr. Odilon Braga (VON UBISCH, 1936). Com grande conhecimento em genética de vegetais, ela também iniciou o estudo sobre a genética de fatores relacionados à reprodução de oxalidáceas, tais como a heterostilia, que seriam de importância fundamental para que se estudasse a influência nesses da infecção por Ustilago (INSTITUTO BUTANTAN, 1935).

\section{Contexto político: "o Caso Butantan” e impressões da cientista}

Ainda que passando por dificuldades de acomodação em seu novo ambiente de trabalho no ano de 1935 num país distante do seu e de língua latina, entusiasmo não lhe faltou, relatando, ainda, no seu primeiro relatório ao Diretor do Instituto: "experiências prometedoras em enxertos de Bolanáceas e Malváceas sobre o transporte de vírus em plantas fui obrigada a desistir temporariamente, por não estar ainda a minha disposição a estufa do jardim, sendo ocupada por outra seção" (INSTITUTO BUTANTAN, 1935).

Apesar de seu entusiasmo, de sua pronta inserção na genética e sorologia animal, foram os fatores políticos relativos ao Instituto que mais a preocuparam e, assim, a envolveriam desde o início de suas atividades. Como a própria Gerta anuncia em suas memórias: "As maiores dificuldades viriam de outro lado, especificamente político". (RICHTER; SCHLECHTER, 2011).

Essas dificuldades podem ser resumidas no que se denominou "Caso Butantan", uma crise institucional resultante de conflitos internos ligados a disputas político-partidárias, essas de natureza externa, sucedidos após a 


\section{Manuscrito aceito}

implantação de parte do ideário de Afrânio do Amaral de institucionalização do Instituto Butantan como Laboratório de Medicina Experimental. O início dessa crise se deu com a ausência de Afrânio, como relatado pela própria Gerta:

"No outono de 1935, houve o Congresso Internacional de Zoologia em Lisboa, ao qual Dr. Afrânio compareceu. No Brasil, existe um ditado que diz: "Quem está ausente não tem amigos". Isto é notavelmente verdadeiro, pois, no Brasil, toda ausência será usada para apoiar as próprias ideias: e assim aconteceu com o Dr. Afrânio. O momento em que isso aconteceu foi uma circunstância muito triste: o chefe do Departamento de Tifo Exantemático de São Paulo da época, Lemos Monteiro, e seu técnico de laboratório, Edison Dias, haviam se infectado durante a produção do soro para essa doença terrível, e morreram poucos dias depois. Esta tragédia foi para o Butantã o que o Atentado de Sarajevo ${ }^{12}$ foi para a Europa: acabou com o trabalho pacífico de décadas. Os que ficaram, chefes de departamento avessos ao diretor - com o vice-diretor no comando - redigiram juntos uma denúncia que continha 44 tópicos, onde o acusavam de todas as contravenções e infrações existentes. A morte dos dois homens foi escolhida como ponto de partida para culpá-lo por não ter disponibilizado o equipamento necessário para proteção contra a infecção. Era praticamente certo de que essa acusação não tinha fundamentos, ainda o vice-diretor tendo podido adquiri-lo, pois não era caro. É possível que eles tenham se infectado por terem se descuidado - como sempre acontece quando alguém lida com material perigoso por muito tempo. (Quantas vezes eu não vi técnicos de laboratório no Butantã serem picados por cobras ao tirarem seu veneno, pensando serem imunes após tantas picadas e manipulação de soros? Nem sempre é o caso!)" (RICHTER; SCHLECHTER, 2011).

Segundo Gerta, além da ausência de Afrânio em território nacional, o perfil extremamente autoritário dele desagradava a seus colegas brasileiros que já estavam no Instituto Butantan há mais tempo. Ainda segundo Gerta, ele trabalhara por alguns anos em um serpentário nos EUA, o "Antivenin Institute of America", e, por isso, estava acostumado a um ritmo diferente de trabalho. Talvez por esse motivo preferisse estrangeiros, os quais possuíam uma

\footnotetext{
${ }^{12}$ O atentado de Sarajevo em 28 de julho de 1914, quando o arquiduque herdeiro do trono austro-húngaro Franz Ferdinand e sua esposa Sophie foram assassinados, desencadeou a Crise de Julho, que levou à Primeira Guerra Mundial.
} 


\section{Manuscrito aceito}

formação mais sólida e eram mais diligentes (RICHTER; SCHLECHTER, 2011).

Diferentes parágrafos da denúncia contra Afrânio citavam as instalações do departamento de Química, compatriotas de Gerta, contando com pesquisadores alemães e técnicos brasileiros de origem germânica, onde a língua utilizada era o alemão. As acusações eram de uso incorreto do dinheiro do Instituto do Café no estudo de venenos. Segundo Gerta: "Não se pode negar que, mais tarde, sairiam trabalhos excelentes deste departamento, mas é igualmente necessário mencionar que, nos primeiros e mais críticos anos, eles pertenciam a uma área completamente diferente à qual foi destinada a verba do Instituto do Café. Fizeram pesquisas sobre venenos de cobras, e não sobre café. (Na verdade, o chefe do departamento havia sido mal informado na Alemanha de que deveria pesquisar sobre café, e não sobre venenos, assim como eu mal sabia que iria trabalhar com cavalos, e ajustou os equipamentos de laboratório que havia trazido para o último assunto)" (RICHTER; SCHLECHTER, 2011).

Consta das acusações feitas a Afrânio uma em especial que envolvia Gerta von Ubisch. "Entre os profissionais estrangeiros contratados pelo Dr. Afrânio do Amaral existe uma técnica que devia conhecer genética animal, para a que foi contratada, entretanto, só trabalha em genética vegetal, assunto alheio às finalidades do Butantan, já em franco desenvolvimento no Instituto Agronômico de Campinas (IAC), que aliás está sob a direção de um brasileiro" (AMARAL, 1941, p 83). Segundo Gerta, tratava-se de $\mathrm{Krug}^{13}$, que havia feito seu curso secundário na Alemanha. Quanto ao fato de Gerta ser uma geneticista vegetal e não animal, ela tem uma explicação bastante pitoresca que envolveriam os acusadores. "Para entender isso, eu tenho que fazer uma explicação breve. Em alemão, a raiz e base do caule no processo de enxerto chama-se "Unterlage", e o broto de cima, "Reis". Em português, a base do enxerto se chama "cavalo". O Dr. Afrânio foi acusado de ter lido que eu trabalhava com enxertos de plantas e, entender erroneamente o termo

\footnotetext{
${ }^{13}$ Carlos Arnaldo Krug formou-se em 1928 engenheiro agrônomo pela Escola Superior de Agricultura "Luiz de Queiroz" (Piracicaba, SP). Ingressou em 1928 no Instituto Agronômico de Campinas (IAC) e trabalhou como assistente na recém-criada Seção de Genética durante os anos de 1929 e 1930, quando iniciou pesquisas sobre o cafeeiro. Em 1932 titulou-se (M.S.) na Cornell University (EUA), especializando-se em genética, citogenética e melhoramento de plantas.
} 


\section{Manuscrito aceito}

"cavalo", e ainda assumido que eu teria trabalhado com cavalos e, ele consequentemente teria me deixado vir para trabalhar com estes. (Certamente se tratava apenas de um trocadilho engraçado que ninguém poderia levar a sério, pois eu nunca publiquei nada em português, nem poderia ter usado a palavra "cavalo"; além do mais, eu nunca publiquei nada sobre enxertos)".

Em sua defesa, Afrânio enaltece as capacidades de Gerta von Ubisch. Ele a descreve como uma pesquisadora de renome mundial encarregada pelo governo imperial da velha Alemanha de dirigir as fazendas especiais de seleção em Petkus e Eckendorf-Hovedissen. Ainda afirma que Gerta, apesar do preconceito germânico em relação às mulheres, ocupava a cadeira de Genética na tradicional Universidade de Heidelberg. Quanto ao fato de ela ser geneticista vegetal e não animal, Afrânio utiliza justificativas muito semelhantes às dadas por Gerta a Bresslau ao saber que trabalharia com melhoramento na produção de soros em cavalos, já observado acima. Repetindo, Gerta observara, ao aceitar o convite para trabalhar no Instituto Butantan: "No fim, só existe uma Genética para o ser humano, os animais e as plantas" (RICHTER; SCHLECHTER, 2011). E Afrânio profere em sua defesa: “... eles ignoram essa coisa banalíssima, que qualquer estudante de biologia lhes poderia repetir, de não haver, entre genética animal e genética vegetal, diferença senão de nome: suas leis são as mesmas e idênticos seus princípios técnicos; o que fez Mendel criador da doutrina, em relação a certas ervilhas, repetiu-o Morgan ${ }^{14}$ de referência com as moscas. Mas isto é assunto demasiado difícil para ser alcançado por qualquer um..." (AMARAL, 1941).

\section{As experiências com os preás domesticados e os selvagens}

No Relatório de Gestão de 1936, Afrânio do Amaral declara seu próprio afastamento da Direção do Butantan de janeiro a novembro para processo de sindicância, quando então as denúncias foram apuradas e a defesa feita, seguindo-se a reintegração de Afrânio como diretor Instituto Butantan no mesmo ano.

\footnotetext{
14 Thomas Hunt Morgan (1866-1945). Após a redescoberta das Leis de Mendel, Morgan iniciou trabalhos com camundongos e ratos. Porém, em 1909 direcionou seus estudos para mosca das frutas (Drosophila melanogaster) por se tratar de um modelo animal mais adequado aos estudos genéticos dado o número de descendentes na prole, ciclo de vida mais rápido e fenótipos bem definidos e de fácil observação, tais como formato das asas, cor do corpo e cor dos olhos. Seu laboratório na Columbia University foi conhecido como "Salas das Moscas" ("The Fly Room") e teve grande importância para história da Biologia, onde foram desvendados vários fatos da ciência, como herança ligada ao sexo, mapeamento gênico, epistasia e os alelos múltiplos. Recebeu o Prêmio Nobel por mostrar que os genes estão localizados nos cromossomos.
} 


\section{Manuscrito aceito}

Em 1936, pequenas melhoras no Laboratório Experimental de Genética foram relatadas. Com a gaiola de proteção pronta em 1936 (Figura 3), cerca de 150 variedades diferentes de aveia foram plantadas. No entanto, a colheita não foi grande, servindo unicamente para a manutenção das variedades. Observações iniciais sugeriam a Gerta que algumas variedades originárias da América do Norte fossem muito apropriadas ao nosso clima e nossas terras. Assim, um novo plantio foi realizado em outubro de 1936, cujos resultados mostraram que uma dessas variedades norte-americanas seria muito superior a outras, sugerindo a ampliação dela. Quanto ao milho, cruzamentos foram realizados entre variedades brasileiras e norte-americanas, sendo que nesse caso, esperar-se-iam resultados definitivos em alguns anos (INSTITUTO BUTANTAN, 1936).

Foi dado início à criação dos híbridos entre cobaios domesticados (Cavia porcellus L.) e preás selvagens (Cavia rufescens Lund), assim como a avaliação da diferença da capacidade de imunização dos parentais contra a anatoxina diftérica. Como resultado das investigações em colaboração com Dra. Jandyra Planet do Amaral da Seção de Imunologia, ficou claro do ponto de vista sorológico que, enquanto os cobaios domesticados reagiam facilmente ao antígeno diftérico, os preás selvagens dificilmente reagiam ao mesmo antígeno, apresentando uma capacidade muito menor de produção de soro antitoxina diftérica, ainda que ambas espécies fossem igualmente sensíveis à fração tóxica da toxina diftérica. Esses resultados preliminares foram publicados nas Memórias do Instituto Butantan (VON UBISCH, AMARAL, 1935-1936).

Assim, quando se mostrou o comportamento diverso entre cobaios domesticados e selvagens quando imunizados com anatoxina diftérica, ficou claro que era imprescindível que os cobaios domesticados fossem de uma linhagem pura para a certificação dos resultados. No entanto, não havia garantias de que todos os cobaios domesticados do Instituto fossem puros de fato. Assim, em 1937 alguns objetivos foram traçados. O primeiro foi a obtenção de uma raça pura de cobaios domesticados. Depois, a ampliação dessa criação para que então se pudesse eliminar os cobaios domesticados já existentes. Depois, realizar o cruzamento da raça pura com preás para determinação de fatores genéticos relativos à potência do soro neutralizante. 


\section{Manuscrito aceito}

Finalmente, repetir os estudos feitos com difteria, além de iniciar estudos com outras moléstias.

Cobaios apropriados para estudos soroterápicos foram obtidos de Göettingen através do professor Köenig, os quais foram utilizados para iniciar a nova criação e para cruzamento com os preás selvagens. No entanto, ainda no ano de 1936 não foi possível a utilização desses novos cobaios, uma vez que esses não haviam se reproduzido suficientemente para os experimentos a seguir. Ainda utilizando de cobaios domesticados dos biotérios do Instituto Butantan e da Faculdade de Medicina de São Paulo, foi possível obter híbridos com $1 / 2$ e $3 / 4$ de preá, teoricamente. Em colaboração com Dr. Ariosto Büller Souto, da seção de Imunologia, foram estudados os perfis sorológicos da cobaia domesticada (Cavia porcellus L.) e do preá (Cavia rufescens Lund) frente aos antígenos tetânicos. Os estudos iniciais mostraram que os cobaios domesticados eram nitidamente mais suscetíveis à toxina tetânica do que os preás. Diferentemente dos estudos com anatoxina diftérica, a anatoxina tetânica parecia imunizar tão bem os cobaios domesticados quanto os preás, embora a curva de imunização fosse diferente. O grande avanço, no entanto, se deu ao estudar uma segunda geração de híbridos. O estudo desses mostrou que alguns cobaios domesticados poderiam ser híbridos e não puros, justificando de fato a necessidade de obtenção de uma raça pura desses para os estudos sorológicos para obtenção de resultados com menor variabilidade. Concluindo, a presença de preás e cobaios domesticados num mesmo biotério seria desaconselhável. Esses estudos foram publicados na revista Memórias do Instituto Butantan (INSTITUTO BUTANTAN, 1937; SOUTO; VON UBISCH, 1938-1939).

No que diz respeito aos trabalhos com plantas, as culturas de aveia foram continuadas com o objetivo de se descobrir qual seria a melhor época para a semeadura das variedades já selecionadas, evitando-se o ataque da ferrugem. As culturas de milho foram abandonadas por falta de espaço para conservação de produtos de cruzamento das diversas variedades a serem selecionadas (INSTITUTO BUTANTAN, 1937).

Ainda em 1937, por ato de 28/04/1937 publicado em 30/04/1937, Gerta von Ubisch foi designada a substituir o assistente Waldemar Peckolt. 


\section{Manuscrito aceito}

Vale lembrar que, logo ao chegar ao Instituto Butantan, o contato de Gerta com Waldemar Peckolt não se mostrou muito profícuo como relatado em sua biografia:

\footnotetext{
"Seu avô era botânico, seu pai, químico, e ele reforçou sua autoridade ao afirmar, como ele mesmo me disse, a "herança" botânica e química de seus antecessores. Porém, essa herança botânica não era grande. No início do meu período lá, se eu o perguntasse o nome de uma planta, ele traria uma das quinze gigantescas edições disponíveis da Flora Brasiliensis de Friedrich von Martius, do início do século XIX, com diagnósticos em latim e tabelas enormes, folhearia até encontrar uma planta com folhas parecidas e explicaria: "Esta aqui". Quando eu, depois de pesquisar, finalmente descobria como ela de fato se chamava e, crendo em seu interesse, compartilhava a informação, ele retrucava que, neste clima, as plantas mudavam de tal forma que pertenciam a outras famílias!" (RICHTER; SCHLECHTER , 2011).
}

Em colaboração com o Dr. Erwin Spielberg da Universidade do Rio de Janeiro e seu sobrinho, experiências foram feitas sobre o sexo dos mamões (INSTITUTO BUTANTAN, 1937). Também, deu-se início à pesquisa de uma variedade de Lupinus (tremoço doce) onde as vagens não abriam ao amadurecer, como acontecia na Alemanha, provocando a dispersão dos caroços pelo chão (INSTITUTO BUTANTAN, 1937).

\section{Licença médica}

Ainda em 1937, Gerta solicita licença saúde. Problemas oftalmológicos sempre a afligiram, como pode-se perceber pela utilização de óculos em fotos da época. Um forte astigmatismo foi piorando durante sua permanência em São Paulo, e consultas recorrentes sugeriam que agora ela tinha uma espécie de catarata rara. A licença foi publicada em 25/06/1937 a contar a partir de 10/07/1937 por três meses, com prorrogação por mais três meses a partir de 10/10/1937 (INSTITUTO BUTANTAN, 1935 B). Um histórico complicado de catarata de sua mãe e a falta de confiança nos profissionais consultados aqui a levaram a buscar ajuda na Europa novamente. Durante essa licença saúde, Gerta foi para a Europa para ser tratada pelo Prof. Sigurd Hagen, em Oslo. A 


\section{Manuscrito aceito}

escolha recaía no fato de seus irmãos estarem morando em Bergen, na Noruega, desde o outono de 1936, os quais providenciaram o contato com o especialista (RICHTER; SCHLECHTER, 2011).

Durante sua saída para a Europa, ela foi substituída pelo seu assistente Raul Franco de Mello, que na época trabalhava na Secção de Endocrinologia e Fisiologia. Segundo Gerta, Franco de Mello já vinha auxiliando-a na Secção de Genética desde abril de 1937. No entanto, como despendia parte de seu tempo com a secção de origem e estudos universitários, seus serviços não tinham maior destaque (INSTITUTO BUTANTAN, 1937), ainda que viessem a publicar o último conjunto de resultados em revista de genética internacional importante.

A operação da catarata de Gerta foi extremamente bem-sucedida, resultando na resolução da opacidade da visão e redução de 8 dioptrias de seu astigmatismo. É curioso notar a observação feita por ela em sua biografia ao declarar suas impressões quanto ao uso de óculos no Brasil da época:

"Hagen esperava que, depois da operação, eu não precisasse mais de óculos para ver de longe: eu não tive tanta sorte, mas eu fui poupada da péssima visão embaçada da qual eu sempre tive pavor. Também não teria sido muito possível atuar em um cargo público no Brasil com aqueles óculos, pois as pessoas são muito sensíveis à aparência das mulheres" (RICHTER; SCHLECHTER, 2011).

Assim, ela antecipou seu retorno para 16/12/1937, dando prosseguimento aos estudos com imunizações de preás contando com a colaboração de Raul Franco de Mello. De fato, estes foram os últimos relatos das pesquisas de Gerta no Instituto Butantan. Os resultados mostraram as diferenças genéticas entre Cavia rufescens e Cavia porcellus, além de seus híbridos interespecíficos com relação à curva de crescimento, anatomia do crânio, ciclo sexual e tempo de gestação (VON UBISCH; MELLO, 1940).

\section{A saída de Afrânio do Amaral e as demissões dos cientistas}

Quando Adhemar de Barros, hostil em relação ao Dr. Afrânio, foi nomeado Interventor Federal do Estado de São Paulo em 27/04/1938, imediatamente Afrânio do Amaral foi substituído pelo interino José Bernardino 


\section{Manuscrito aceito}

Arantes, um dos denunciantes de Afrânio no "Caso Butantan" e aliado de Adhemar. É criado, então, o Serviço do Laboratório de Saúde Pública, compreendido pelos Institutos Butantan, Pasteur e Bacteriológico, o qual seria dirigido pelo Dr. Jayme Cavalcanti, que também acumularia a Direção do Instituto Butantan (IBAÑEZ; SANT'ANA, 2011).

Cabe aqui registrar a visão de uma cientista nascida no exterior, Gerta von Ubisch, quanto ao afastamento de Afrânio do Amaral e suas consequências para o grupo de cientistas estrangeiros contratados em 1934. Segundo Gerta, o ex-vice-diretor José Bernardino Arantes adentrou a sala de Afrânio e entregou-lhe uma carta do interventor, segundo a qual ele estaria deposto, exigindo que ele saísse imediatamente do Instituto. Conta ainda Gerta:

\footnotetext{
"Depois de o Dr. Afrânio ser expulso, o novo diretor passou por todos os departamentos expulsando as pessoas que o primeiro tinha contratado e, recontratando todos os que ele expulsou. Entrar no departamento de Química foi proibido por semanas, e tudo foi investigado por provas de que ele havia usado os equipamentos ilegalmente para seus próprios interesses comerciais - o que obviamente não era verdade. $O$ precioso departamento foi todo entregue a um técnico de laboratório e esposa; isso o arruinou completamente. Ele recebeu a tarefa de produzir penicilina, e surgiram artigos nos jornais sobre o novo casal Curie (este técnico e a esposa) como se fossem milagreiros. Eles, na verdade, compravam a penicilina, pois sequer podiam produzi-la, a colocavam em uma outra embalagem e a revendiam como produto do Butantan" (RICHTER; SCHLECHTER, 2011).
}

O Diretor informou pessoalmente à Gerta sobre o término das atividades de sua Seção. Disse à mesma que nenhum trabalho teórico deveria ser feito, somente prático. E como, segundo ele, o trabalho dela só tinha interesse teórico, ela deveria interrompê-lo. Ainda disse que não a impediria de continuar trabalhando no Butantan, mas que ela não contasse com nenhum pagamento. Ela poderia considerar o material coletado como propriedade pessoal dela, pois seria completamente inútil ao Instituto (RICHTER; SCHLECHTER, 2011). 


\section{Manuscrito aceito}

Deve-se considerar que a abordagem científica de Gerta já havia chegado a um resultado de incrível significância para todos os institutos brasileiros que usavam preás. Através de seus estudos, ficou estabelecido que não é possível imunizá-los contra veneno de cobra e difteria e, ainda, que o cruzamento com os cobaios produz material que não é confiável, ou seja, apresenta perfil sorológico diverso, podendo variar por todo espectro de produção de soro. Como todos os biotérios brasileiros tinham um componente selvagem misturado de fácil reconhecimento pela pelagem aguti, que só ocorre em preás selvagens consanguíneos ou puros, tornou-se imprescindível introduzir um grupo completamente novo de uma localidade onde nunca houve um componente selvagem nas gerações anteriores e substituir todos os outros preás por esses. Gerta já havia iniciado esse procedimento com cobaios que vieram de Göettingen, como relatado acima. Em sua biografia, ela descreve sua busca por alguma instituição científica que pudesse lograr com seu trabalho até então realizado e, especificamente receber os animais por ela selecionados. Infelizmente, nenhum instituto de gestão pública foi encontrado pois, segundo ela, ninguém ousaria a apoiar os cientistas desacreditados pelo interventor. Um instituto de diagnóstico privado deu abrigo a seus animais, mas logo esses morreram por manejo inadequado (RICHTER; SCHLECHTER, 2011). E assim perdeu-se um trabalho em potencial em meio a uma desavença política. Gerta ainda afirma que, logo após a publicação de seus resultados com Jandyra P. do Amaral em uma revista holandesa, um sorologista de renome - segundo a mesma, o mais respeitável sorologista alemão -, o Prof. Prigge, de Frankfurt, Ihe escreveu cumprimentando-a pelo material e resultados obtidos, dando conselhos a respeito do que fazer com esse material único. No entanto, quando Gerta recebeu a carta, o material já não existia mais (RICHTER; SCHLECHTER, 2011).

Coincidentemente, no mesmo dia em que todos os estrangeiros foram dispensados do Instituto Butantan, Gerta teve a notícia do suicídio de seu sobrinho Erwin Spiegelberg. Em sua biografia, ela relata a insatisfação de Erwin com uma nomeação que no último momento foi cedida a outra pessoa, junto a provável notícia da dispensa de Gerta - eles ainda planejavam trabalhar 


\section{Manuscrito aceito}

juntos -, aliado a uma profunda solidão no Rio de Janeiro (RICHTER; SCHLECHTER, 2011).

Gerta teve seu contrato rescindido em 23/06/1938. A justificativa oficial se baseava no fato de o Instituto Butantan deixar de ser independente, sendo incorporado à Diretoria Geral do Serviço Sanitário. Assim, a Seção de Citologia, Embriologia e Genética seria extinta e, por conseguinte, não seriam mais necessários os serviços de Ubisch, assim como o de outros assistentes do Instituto (INSTITUTO BUTANTAN, 1935B).

Vários cientistas do Instituto receberam a demissão por escrito, incluindo o assistente de Ubisch à época, Raul Franco de Mello. No entanto, a mesma não recebeu a comunicação, assim como não houve publicação em Diário Oficial. Esse erro burocrático resultaria na falta de recebimento dos proventos que deveriam ser destinados a ela. Quando questionou o ocorrido, Gerta recebeu a informação de que não fazia mais parte da lista de pagamentos. Em 01/02/1939 ela requereu o pagamento de junho de 1938 a janeiro de 1939 mais as férias de direito, o que foi negado em 08/08/1939 e definitivamente negado em 18/09/1939, finalizando sua passagem pelo Instituto Butantan.

Dr. Willy Beçak, ex-Diretor do Laboratório de Genética e do Instituto Butantan, ainda relata o destino do material restante de Gerta von Ubisch no instituto: "Ela era geneticista alemã e tinha vindo para o Brasil onde, no Instituto Butantan, começou a trabalhar com hibridização de cotia e de cobaia para conseguir um animal de laboratório mais resistente e melhor. Ela tinha uma série de dados, mas naquelas brigas que aconteceram no Butantan acabou saindo. Fizeram uma pilha no meio do pátio onde puseram todos os crânios e tudo o que ela tinha, incluindo os trabalhos, e atearam fogo. Isso não está registrado, mas isso aconteceu" (BEÇAK, 2008).

Em 1939, Ubisch obteve uma posição de um ano no Ministério da Agricultura. No entanto, após 1940 passou a não ter mais um cargo permanente. Entre outras coisas, ela trabalhou no setor agrícola e deu aulas de biologia em São Paulo. A partir desse momento, a biografia de Gerta inicia sua trajetória pelo Rio de Janeiro e Rolândia, no Paraná, até que ela retorna para a Europa, o que é importantíssimo para o desenho de sua carreira. Apesar de 


\section{Manuscrito aceito}

fugir aos objetivos desse artigo, finalizaremos com um breve relato de seu retorno a Europa e sua luta pelo seu reconhecimento na Alemanha no período do pós guerra. (DEICHMANN, 1996; RICHTER; SCHLECHTER, 2011).

\section{O Retorno de Gerta von Ubisch à Europa}

Após a guerra, ela imediatamente buscou um visto para a Noruega, onde seu irmão Leopold von Ubisch estava vivendo com sua família. Demorou um ano e meio para que ela recebesse permissão para entrar na Noruega, como resultado do empobrecimento desse país pela ocupação alemã. De fato, declarações oficiais norueguesas afirmavam que, em princípio, a entrada de estrangeiros não era permitida. Ela recebeu um visto de um ano, mas a convivência com seu irmão e cunhada tornou-se muito difícil, considerando-se que seu irmão ainda não tinha um cargo permanente na Noruega. Novamente, Gerta tentou outras possibilidades no Brasil. Ela conseguiu uma passagem para o Brasil com um dono de navio em troca de serviços de tradução. Desta vez ela não conseguiu um cargo relacionado a sua profissão e dedicou-se a tarefas domésticas e puericultura para pessoas que conhecia. Após poucos meses, ela retornou para Noruega e depois para a Alemanha (DEICHMANN, 1996).

Em maio de 1952, aos quase 70 anos, Gerta chegou a Heidelberg em condição de pobreza. Por conta de suas dificuldades financeiras, ela solicitou um apoio permanente como compensação ao Ministério da Cultura em Stuttgard em 28/05/1952. O reitor da Universidade, Eberhard Schmidt, deu suporte ao seu pedido, enviando várias cartas ao ministro Walter Jellinek. No entanto, seu pedido foi negado em 12/05/1953. A negativa era baseada no fato de ela não possuir contrato de servidora pública na Universidade de Heidelberg, seja como professora ou como assistente. Sendo uma assistente extraordinária, não possuía direito legal a uma pensão (DEICHMANN, 1996).

Ubisch ficou desapontada com essa decisão tão servil à letra da lei. Ela escreveu ao ministro:

\footnotetext{
"Assim, como você demonstrou-me parágrafo por parágrafo, eu não tenho dúvida que eu não seja candidata à indenização de acordo com a letra da lei. Mas não seria possível colocar à frente um fator
} 


\section{Manuscrito aceito}

humano que amenize injustiças que surgem com toda lei?" (UBISCH APUD. DEICHMANN, 1996).

Schimidt a aconselhou a apelar da decisão para a Corte de Compensação da Corte Regional em Karlsruhe e elaborou a queixa para ela. A queixa sustentava que instrutores particulares ("Privatdozent") não lecionavam privadamente de forma estrita e, assim, pertenceriam à categoria dos trabalhadores "freelancers". Com base na Lei de Habilitação do Reich de 1939, seria muito provável que seria dado a Ubisch um cargo de professora universitária supranumerária ou um cargo de servidora pública correspondente caso a mesma não fosse expulsa da universidade por perseguição racial (DEICHMANN, 1996).

Uma audiência foi marcada para 20/10/1953 presidida pelo Juiz Principal da Corte do Estado ("Landgerichtsdirektor"), Dr. Gotzen, e o advogado Rössinger, representando o Ministro da Cultura. Nenhum protocolo oficial relacionado a esse encontro foi obtido, mas trechos do protocolo elaborado por Ubisch e enviados ao reitor em 24/03/1954 mostram que a corte estava determinada desde o início a rejeitar a apelante. Foi perguntado a Ubisch porque ela não tinha dinheiro algum ainda que seu avô era um homem abastado, e ela teve que justificar dizendo que a riqueza de seu avô, morto em 1881, fora perdida devido à inflação e à reforma monetária. No final, ela foi culpada por sua própria situação. "O juiz principal, dr. Goltzen, acusou-me de que tivesse deixado voluntariamente em 1933. A venia legendi (formalidade) me foi restaurada no outono de 1933, então eu deveria continuar ensinando até 1935. Então vieram as Leis de Nuremberg que diziam: qualquer um que estivesse empregado, continuaria. Nesse caso, eu ainda deveria ser professora em 1939 quando a nova Lei de Habilitação do Reich foi publicada, e deveria me tornar uma funcionária pública. Ao deixar voluntariamente e sem causa, eu desperdicei essa chance" (VON UBISCH, APUD. DEICHMANN, 1996). Quando em sua resposta ela abordou o boicote estudantil de suas aulas, entre outros fatores, Rössinger rejeitou sua reivindicação, declarando que nesses tempos, outros professores judeus continuaram. (DEICHMANN, 1996).

O tribunal propôs um acordo que incluía um pagamento mensal de 150 marcos alemães (DM) por mês, sujeito a ser encerrado a qualquer momento 


\section{Manuscrito aceito}

(DEICHMANN, 1996). Esse foi o reconhecimento de Gerta von Ubisch por parte das autoridades da Alemanha em processo de "desnazificação". Gerta von Ubisch morreu em 1965 e foi enterrada ao lado de sua irmã, Magda, em Marburg.

\section{Considerações finais}

Os estudos aqui apresentados têm como base a visão clara de uma geneticista que, em sua época, na terceira década após a redescoberta das leis de Mendel, se propôs a contribuir com o estabelecimento das bases de uma área ainda incipiente no Brasil, a Genética. De maneira extremamente sólida considerou como fundamental a caracterização de indivíduos parentais para que se possa entender a transmissão de fatores genéticos desses à prole, sejam caracteres associados a produção de soros ou outros caracteres quaisquer. Ademais, questionou a validade de resultados obtidos através de animais criados em biotérios sem controle genético.

Nessa época, foram de fato estabelecidas as bases e boas práticas da Genética. Ainda que a produção de soros em cavalos fosse o objetivo final, a cientista retroagiu a um modelo animal mais simples para estudar a herança desses fatores para, posteriormente, buscar a certificação do modelo através da caracterização precisa desses parentais. Isso feito, se poderia estudar o fluxo de determinados caracteres no decurso de sucessivos cruzamentos, havendo a aplicação posterior em cavalos. A busca de modelos mais adequados a determinados problemas pontua com elegância a história da Biologia. Morgan, como descrito acima, transpôs e validou estudos da genética de plantas para moscas, que eram atrativas pelo curto ciclo de vida prole numerosa, estudando novos tipos de herança nesse modelo. Mais recentemente Sidney Brenner, ganhador do Prêmio Nobel de Fisiologia ou Medicina em 2002, propôs o Caenorhabdits elegans como organismo adequado aos estudos de desenvolvimento, diferenciação celular Apesar de este organismo ser caracterizado por curto um ciclo de vida e ser muito pequeno para um eucarioto multicelular, conhece-se a linhagem celular de todas as células de seu corpo e da genética estudada (BRENNER, 1974). Da mesma forma, numa primeira excursão pelo Instituto Butantan, Gerta vislumbrou os preás como alternativa aos cavalos. Gerta preocupava-se com o 


\section{Manuscrito aceito}

estabelecimento de uma disciplina num Instituto ainda sem tradição nessa área e, para tanto, implantava e discutia aquilo que fosse fundamental de natureza teórica ou prática dessa nova disciplina durante seu período no Instituto Butantan.

O argumento desenvolvido neste artigo sobre o papel de Gerta Von Ubisch na criação e desenvolvimento do Laboratório de Genética no Instituto Butantan, utilizando os conceitos de "ciência em construção" e a ideia de uma rede de agentes para a construção da ciência, traz dois aspectos relevantes para entender o "fazer a ciência" numa fase incipiente de organização de uma instituição científica pública brasileira: os contextos institucionais e políticos específicos do período como fatores intervenientes e as possiblidades e os resultados alcançados pelos cientistas. Assim, seria impossível, por exemplo, descrever a vinda de Gerta para o Brasil sem considerar o estabelecimento de regimes totalitários na Europa entre guerras e antissemitismo.

Os relatos de seus trabalhos aqui expostos, como as duas encomendas realizadas pelo então diretor (forragens e animais para produção de soros), as condições de trabalho bastante rudimentares, os contatos e a importância das parcerias com os colegas e cientistas brasileiros corroboram os conceitos de que a ciência se constrói com ideias, conhecimento e práticas, transformando situações adversas e laboratórios improvisados em ações e conhecimentos produtivos.

Esperamos que este artigo possa, de fato, contribuir para uma historiografia da ciência desmistificadora, mais próxima do real e para a construção de uma memória institucional relevante para o Instituto Butantan, podendo influir de maneira positiva na formação de novos cientistas.

\section{Referências}

Amaral A. Serpentes em crise: À Luz de uma legítima defesa no "Caso do Butantan", São Paulo: Editora Revista dos Tribunais, 1941. 


\section{Manuscrito aceito}

Beçak W. Sobre a história da genética no Instituto Butantan (Entrevista com Willy Beçak). Cadernos de História da Ciência.2008;4(1):118-11).

Brenner S. The genetics of Caenorhabditis elegans. Genetics. 1974;77(1):7194.

Buller Souto A, Ubisch G. Comportamento da cobaia (Cavia porcellus L.) e do preá (Cavia rufescens Lund) em relação aos antígenos tetânicos. Mem. Inst. Butantan. XII: 1938-39.

Deichmann U. Biologists under Hitler. Dunlap T, tradutor. Cambridge: Harvard University Press; 1996.

Deichmann U. Women and Genetics in Germany: research and Careers until 1950. In: Rn, Eh, Mv, editores. Elisabeth Schiemann 1881-1972 Vom AufBruch der Genetik und der Frauen in den UmBrüchen des 20. Rangsdwam.orf: Basilisken-Presse.;2014. p. 26-53

Hawgood, BJ. Slotta, KH (1895-1987) biochemist: snakes, pregnancy and coffee. Toxicon. 2001 Sep;39(9):1277-82.

Ibañez N, Fernandes SCG, Faria M, Wen FH, Sant'Anna OA.. De Instituto Soroterápico a Centro de Medicina Experimental: institucionalização do Butantan no período de 1920 a 1940. Cad. Hist. Ciênc. 2006, 2(1)

Ibanñez N, Sant'Anna OA. in Instituto Butantan: a pesquisa e o desenvolvimento tecnológico em São Paulo.

Latour B. A ciência em ação: como seguir cientistas e engenheiros sociedade afora. Benedetti IC, tradutor; Assis JP, revisor. São Paulo: Editora Unesp; 2000.

Kuhn TS. A estrutura das revoluções científicas. Boeira BV, Boeira N, tradutores. São Paulo: Editora perspectiva; 2006.

Instituto Butantan. Prontuário funcional de Gerta von Ubisch (1935-1938). São Paulo: Instituto Butantan , 1935b.

Instituto Butantan, Seção de Genética Experimental. Relatório de gestão: 1935. São Paulo: Instituto Butantan , 1935.

Instituto Butantan, Seção de Genética Experimental. Relatório de gestão: 1936. São Paulo: Instituto Butantan , 1936.

Instituto Butantan, Seção de Genética Experimental. Relatório de gestão: 1937. São Paulo: Instituto Butantan , 1937.

Remy, Steven P. The Heidelberg Myth: The Nazification and Denazification of a german University. Cambridge: Harvard University Press; 2002.

Richter S, Schlechter A, editores. (2011) Zwischen Allen Welten: Die Lebenserinnerungen Der Ersten Heidelberger Professorin Gerta Von Ubisch (German Edition). Stuttgard: Finken \& Bumiller, 2011. 


\section{Manuscrito aceito}

Slotta KH, Fraenkel-Conrat H. Crotoxin. Nature. 1939;144: 290-291.

Stamhuis IH, Vogt AB. Discipline building in Germany: women and genetics at the Berlin Institute for Heredity Research. British Journal for the History of Science. 2017;50(2).

Von Ubisch G. Estudo sobre fêmeas, machos e formas sexuais aberrantes em Antennaria dioica (L.) Gaertn. Mem. Inst. Butantan. 1935-1936;tomo X.

Von Ubisch G. Genetic Studies on the Nature of Hermaphroditic Plants in Antennaria Dioica (L) Gaertn. Genetics. 1936 May;21(3):282-94.

Von Ubisch G.A alteração da morfologia de flores pelos Ustiginales. Annaes da primeira reunião de phytopathologistas do Brasil.1936; 323-327.

Von Ubisch G, Amaral JP. Diferença da capacidade de imunização da cobaia (Cavia porcellus L.) e do preá (Cavia rufescens, Lund) contra a anatoxina diftérica. Mem. Inst. Butantan.1935-1936; tomo X.

Von Ubisch G, Mello RF. Genetic studies on a cavy species cross: Cavia rufescens (Lund) and Cavia porcellus (Linné). Journal of Heredity. 1940; 31(9):389-398.

IBAÑEZ, Nelson; SANT'ANNA, Osvaldo Augusto. Instituto Butantan: a pesquisa e o desenvolvimento tecnológico da saúde em São Paulo. In: NATALINI, Gilberto; AMARAL, José Luiz Gomes do (org.).450 anos de história da medicina paulistana. São Paulo: Imprensa Oficial, 2004, p. 318-364.

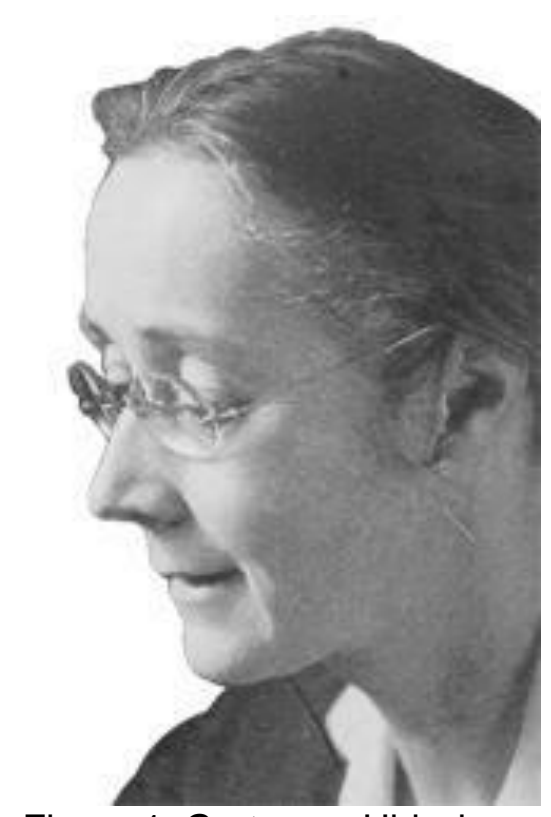

Figura 1. Gerta von Ubisch.

Fonte: https://www.ub.uni-

heidelberg.de/ausstellungen/625jahre2011/sektion2/ubisch.html 


\section{Manuscrito aceito}

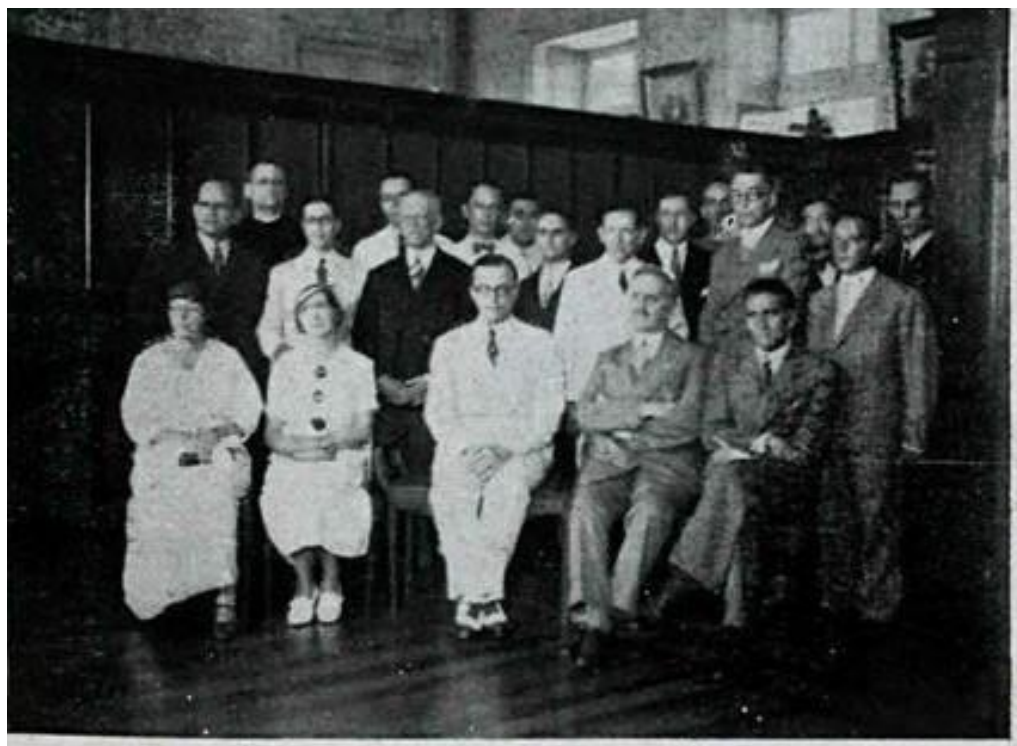

O Exmo. Snr. Ministro da Agricultura Dr, Odilon Braga, tendo á direita o Prof. Raul Leitáo da Cunha, Reitor da Unisersidade do Brasil e o Dr. A. Bitancourt e á esquerda as Dras. Anne Jenkins e Gerda von Uhisch.

Em pé, da direita para a esquerila: Drs. N. Azevedo, A. Máller, A. Coelho, P. Campos Porta D. Pacea, H, Grillo, A. Puttemans, B. Novaes, A. F. Magarinos Torres, Armando Vidal Alfredo da Matta, A. Barreto, N. Fagundes, Pe, J. Rick e J. G. Carnciro,

(Photographia tirada na Escola Nacional de Agronomia, em 21.1.936, mamentos antes da Sessio Inaugural da Primeira Reunilio de Phytopathologistas do Brasil).

Figura 2. Participação de Gerta von Ubisch na primeira reunião de fitopatologistas do Brasil em 21/01/1936 no Rio de Janeiro.

Fonte: Annaes da primeira reunião de phytopathologistas do Brasil (1936).

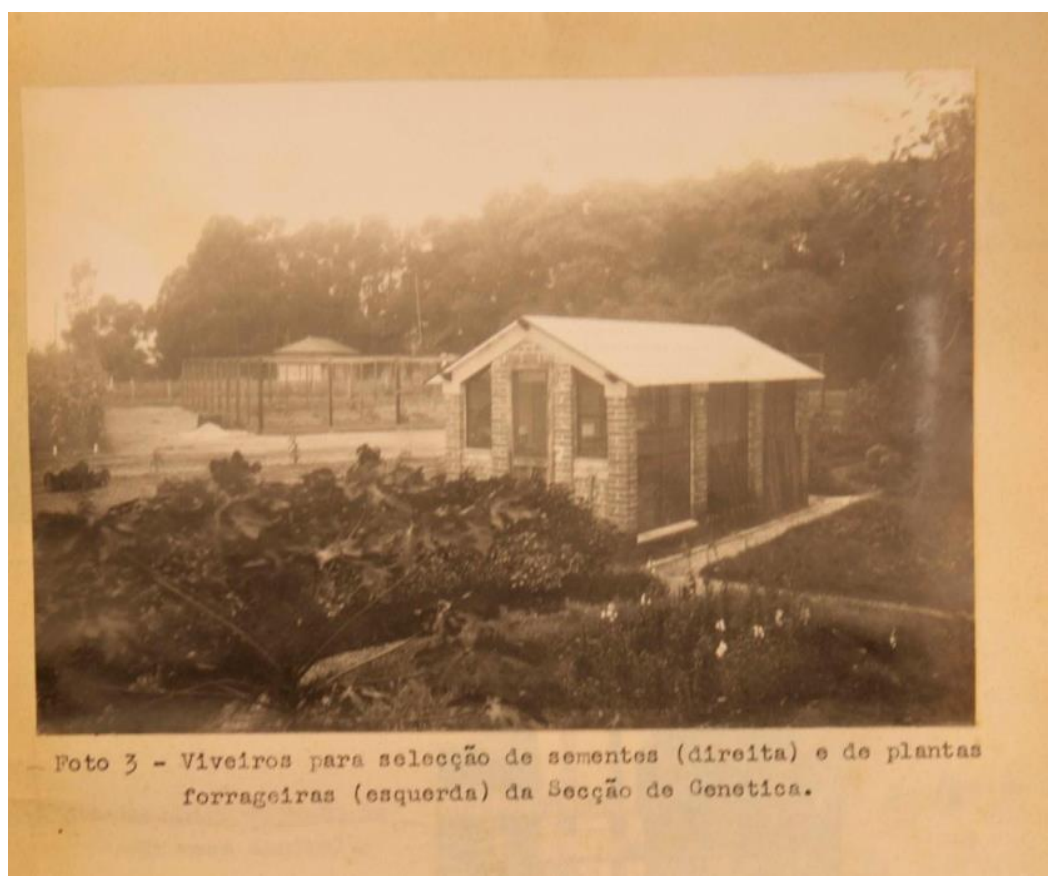

Figura 3. Viveiros (gaiolas) de plantas do Laboratório de Genética.

Fonte: Acervo iconográfico do Instituto Butantan. 